\title{
Paracrine Mechanisms of Intravenous Bone Marrow-Derived Mononuclear Stem Cells in Chronic Ischemic Stroke
}

\author{
Ashu Bhasin $^{a} \quad$ M.V. Padma Srivastava ${ }^{a}$ Sujata Mohanty ${ }^{b}$ \\ Sivasubramaniam Vivekanandhan ${ }^{c}$ Sakshi Sharma ${ }^{a}$ Senthil Kumaran ${ }^{d}$ \\ Rohit Bhatia ${ }^{a}$ \\ Departments of a Neurology, ${ }^{b}$ Stem Cell Facility, ${ }^{c}$ Neurobiochemistry, and ${ }^{d}$ Nuclear \\ Magnetic Resonance, All India Institute of Medical Sciences, New Delhi, India
}

Key Words

Intravenous bone marrow-derived mononuclear stem cells - Chronic ischemic stroke ·

Autologous mononuclear stem cell infusion

\section{Abstract}

Background: The emerging role of stem cell technology and transplantation has helped scientists to study their potential role in neural repair and regeneration. The fate of stem cells is determined by their niche, consisting of surrounding cells and the secreted trophic growth factors. This interim report evaluates the safety, feasibility and efficacy (if any) of bone marrow-derived mononuclear stem cells (BM-MNC) in chronic ischemic stroke by studying the release of serum vascular endothelial growth factor (VEGF) and brain-derived neurotrophic growth factor (BDNF). Methods: Twenty stroke patients and 20 age-matched healthy controls were recruited with the following inclusion criteria: 3 months to 1.5 years from the index event, Medical Research Council (MRC) grade of hand muscles of at least 2, Brunnstrom stage 2-5, conscious, and comprehendible. They were randomized to one group receiving autologous BM-MNC (mean 60-70 million) and to another group receiving saline infusion (placebo). All patients were administered a neuromotor rehabilitation regime for 8 weeks. Clinical assessments [Fugl Meyer scale (FM), modified Barthel index (mBI), MRC grade, Ashworth tone scale] were carried out and serum VEGF and BDNF levels were assessed at baseline and at 8 weeks. Results: No serious adverse events were observed during the study. There was no statistically significant clinical improvement between the groups (FM: 95\% CI 15.2-5.35, $p=0.25$; mBI: $95 \%$ CI 14.3-4.5, $p=0.31)$. VEGF and BDNF expression was found to be greater in group 1 compared to group 2 (VEGF: 442.1 vs. 400.3 pg/ml, p = 0.67; BDNF: 21.3 vs. $19.5 \mathrm{ng} / \mathrm{ml}$ ) with- 
out any statistically significant difference. Conclusion: Autologous mononuclear stem cell infusion is safe and tolerable by chronic ischemic stroke patients. The released growth factors (VEGF and BDNF) in the microenvironment could be due to the paracrine hypothesis of stem cell niche and neurorehabilitation regime.

(C) 2016 The Author(s)

Published by S. Karger AG, Basel

\section{Introduction}

The development of regenerative medicine has enthralled researchers to study and exploit its usage and therapeutic effects [1,2]. Different types of stem cells exhibit a potential that has helped improving symptoms of various intractable neuronal diseases, such as stroke $[3,4]$. Bone marrow-derived mononuclear stem cells (BM-MNC) have been used in preclinical studies suggesting increased angiogenesis in penumbral tissue following CD34+ cell transplantation, whether given systemically (intra-arterial, intravenous or intrathecal) or by the intracerebral route $[5,6]$.

Stem cells actively contribute to their environment by secreting cytokines, growth factors and extracellular matrix molecules that act either by themselves (autocrine actions) or on human body and other tissues (paracrine) for regeneration [7]. In addition, these cells secrete angiogenic factors, antifibrotic factors, extracellular matrix homeostasis proteins such as collagens, matrix metalloproteinases and other inhibitors [8]. Brain-derived neurotrophic growth factor (BDNF) crucially promotes the synaptic and axonal plasticity associated with learning, memory and sensorimotor recovery [9]. It stimulates neuronal differentiation in vitro. It has also been used to induce neurogenesis after focal ischemia, thereby increasing the number of newborn neurons in several regions of the brain enhancing neural structural plasticity [10]. Vascular endothelial growth factor (VEGF) is a dimeric glycoprotein mitogenic for endothelial cells. It has been shown to increase vascular permeability; it can induce chemotaxis in monocytes in pathological conditions [11] as well as inhibit endothelial cell apoptosis. Recently, it was shown that both VEGF and its receptor Flt-1 are upregulated in both neurons and blood vessels in the penumbra after transient or permanent occlusion of the middle cerebral artery in the rat [12].

Cell treatment or treatment with a stem cell-containing population is nascent in the current stage and has met enormous skepticism in the field of cell therapeutics. Since the realization that the beneficial effects of stem cells may be due to localized or generalized release of trophic factors, and not attributed (in part or entirely) to stem cell transdifferentiation or homing in to the lesioned cortex, many scientists have focused on harnessing the paracrine actions of stem cells to enhance therapeutic efficacy [13, 14].

The adult brain can regenerate neurons lost after brain ischemia. Repair mechanisms in stroke are related to acute injury (first epoch) and they are said to occur in the initial few hours after the acute event when changes in blood flow, metabolism and ischemic cascade are most active. A second epoch is related to the upregulation of growth factors which continues for days to weeks and is referred to as endogenous repair-related events. A third epoch occurs weeks to months after stroke when spontaneous recovery mechanisms plateau representing a stable but modifiable early and late chronic phase. The objectives were (a) to study safety, feasibility and efficacy (if any) of BM-MNC infusion in chronic ischemic stroke; (b) to study early/late upregulation of serum growth factors (VEGF and BDNF) after BM-MNC and neuromotor rehabilitation after stroke, and (c) to study the correlation of serum VEGF and BDNF with functional recovery after stroke. 

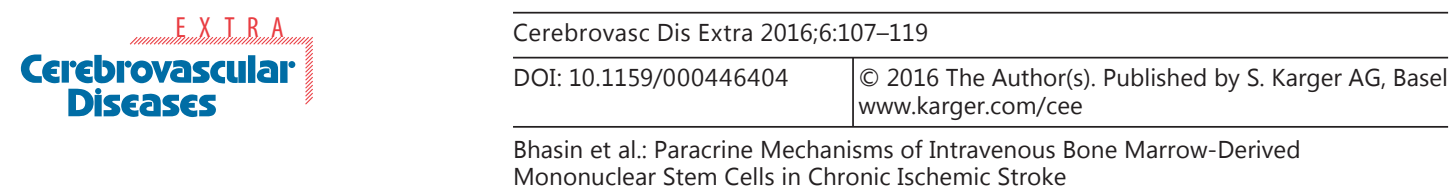

\section{Methods}

Thirty patients were screened who fulfilled the inclusion criteria; among them, 5 refused to participate in the trial and 5 had deranged baseline laboratory values and were therefore excluded; hence, 20 patients were recruited in the study. Patients diagnosed with ischemic stroke 3 months to 1.5 years after the index event with Medical Research Council (MRC) grade of power for wrist and hand muscles of at least 2, Brunnstrom stage of recovery of 2-5, National Institutes of Health Stroke Scale (NIHSS) score of between 4 and 15, being conscious / comprehendible as well as 20 age-matched healthy controls were recruited. The exclusion criteria were hematological disorders, autoimmune disorders, immunocompromised subjects, chronic liver and renal failure, progressive neurological worsening, unilateral neglect, neoplasia, contraindication to MRI and pregnancy. Twenty patients were randomized (computer-assisted) to two groups. One group was infused with BM-MNC and the other group with placebo (i.e. intravenous saline infusion). All patients were administered a neuromotor rehabilitation regime for 8 weeks. Prior to stem cell therapy, patients were screened and educated about the stem cells and bone marrow aspiration technique. Written informed consent was obtained, complete medical history, examination and baseline laboratory tests were performed. The patients were examined by a neurologist and a neurophysiotherapist for muscle strength/power (MRC grade) and tone (modified Ashworth tone scale), Fugl Meyer (FM) scale for upper limb, the Edinburgh handedness inventory and the modified Barthel index (mBI) [15-17]. The study is a randomized placebo-controlled clinical trial which was approved by the IC-SCRT (Institute Committee for Stem Cell Research and Therapy) and is registered with CTRI (CTRI/2014/09/005028). Safety and efficacy end points were assessed at 7 days, 8 weeks, 6 months and 1 year after stem cell transplantation. Serum VEGF and BDNF levels were measured at baseline, 8 weeks, 6 months and 1 year. Functional MRI was also performed at the same time points. The outcome measures were blinded to one of the assessors.

This paper presents an interim analysis of safety, feasibility and efficacy of BM-MNC in chronic ischemic stroke along with the upregulation of the serum growth factors VEGF and BDNF after 2 months of cell infusion.

\section{Bone Marrow Aspiration, Separation and Transplantation}

Bone marrow (approximately 40-50 ml) was aspirated under aseptic conditions from the posterior superior iliac crest in 10 chronic stroke patients. Bone marrow aspirate was diluted with phosphate-buffered saline, layered over Ficoll density medium and centrifuged at 1,800 rpm for $25 \mathrm{~min}$. BM-MNC layers were collected, and the number of CD34+ cells (flow cytometry method) was counted for each patient $[18,19]$ (table 1 ). The cells were manufactured entirely under good manufacturing practice conditions. The mean cell viability of BM-MNC at transplantation was $98 \%$, which was performed with trypan blue stain, and the cells were sterile and endotoxin-free during culture and at transplantation. The whole procedure took approximately $120 \pm 10 \mathrm{~min}$. An aseptic technique of infusion was performed with collected BM-MNC in a 50-ml sterile syringe, which was directly dissolved in $250 \mathrm{ml}$ of saline and infused intravenously over $3 \mathrm{~h}$.

\section{Serum Sampling for VEGF and BDNF}

Samples were immediately centrifuged $(1,500 \mathrm{~g} / 15 \mathrm{~min})$ and serum was stored at $-70^{\circ} \mathrm{C}$ until assayed. Serum VEGF and BDNF levels were measured by standard quantitative sandwich ELISA (Quantikine) kits, obtained from R\&D Systems. Samples from each individual were analyzed in triplicate and subsequently used in all further statistical analysis. The lower limits of detection were $5.0 \mathrm{pg} / \mathrm{ml}$ for VEGF and $3 \mathrm{ng} / \mathrm{ml}$ for BDNF (information provided by R\&D 

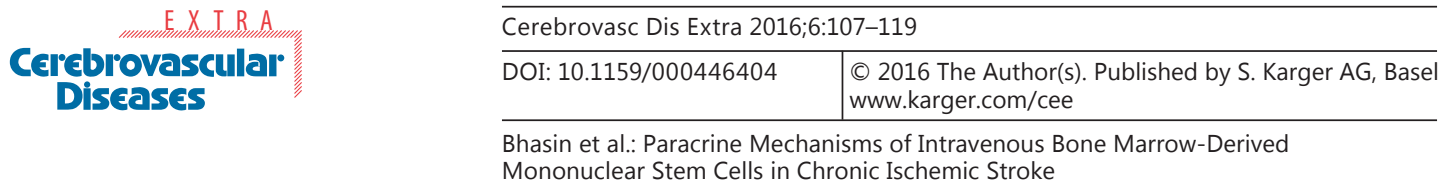

Table 1. Demographics, risk factors and baseline characteristics in groups 1 and 2 and healthy controls

\begin{tabular}{|c|c|c|c|c|}
\hline & $\begin{array}{l}\text { Group 1 } \\
(\mathrm{n}=10)\end{array}$ & $\begin{array}{l}\text { Group } 2 \\
(\mathrm{n}=10)\end{array}$ & $\begin{array}{l}\mathrm{p} \\
\text { value }\end{array}$ & $\begin{array}{l}\text { Healthy controls } \\
(\mathrm{n}=20)\end{array}$ \\
\hline Male & 10 & 10 & & 12 \\
\hline Female & 2 & 3 & & 8 \\
\hline Age, mean $\pm S D$, years & $48.6 \pm 7.1$ & $48.1 \pm 9.1$ & 0.24 & $49.6 \pm 5.6$ \\
\hline Average time to stroke onset, months & 11.6 & 10.5 & & \\
\hline \multicolumn{5}{|l|}{ Risk factors } \\
\hline Hypertension & $7(70 \%)$ & $6(60 \%)$ & 0.15 & $12(60 \%)$ \\
\hline Diabetes mellitus & $5(50 \%)$ & $3(30 \%)$ & 0.87 & $6(30 \%)$ \\
\hline Hypercholesterolemia & $6(60 \%)$ & $4(40 \%)$ & 0.56 & $10(50 \%)$ \\
\hline Smoking & $4(40 \%)$ & $4(40 \%)$ & 0.49 & $13(65 \%)$ \\
\hline Alcohol consumption & $3(30 \%)$ & $2(20 \%)$ & 1.0 & $5(25 \%)$ \\
\hline Tobacco abuse & - & - & 0.58 & $3(15 \%)$ \\
\hline Coronary artery disease & $5(50 \%)$ & $6(40 \%)$ & - & $5(25 \%)$ \\
\hline \multicolumn{5}{|l|}{ Ischemic stroke (subtype) } \\
\hline LA atherosclerosis & $4(40 \%)$ & $4(40 \%)$ & 0.67 & \\
\hline $\mathrm{CE}$ & $4(40 \%)$ & $1(10 \%)$ & 0.35 & \\
\hline SA occlusion & $2(20 \%)$ & $3(30 \%)$ & 0.21 & \\
\hline Others & - & $2(20 \%)$ & 0.81 & \\
\hline \multicolumn{5}{|l|}{ Laboratory parameters } \\
\hline \multicolumn{5}{|l|}{ Baseline } \\
\hline VEGF & $366.2 \pm 78.6 \mathrm{pg} / \mathrm{ml}$ & $370.5 \pm 91.1 \mathrm{ng} / \mathrm{ml}$ & 0.42 & \\
\hline $\mathrm{BDNF}$ & $18.7 \pm 6.6 \mathrm{pg} / \mathrm{ml}$ & $16.1 \pm 7.6 \mathrm{ng} / \mathrm{ml}$ & 0.56 & \\
\hline \multicolumn{5}{|l|}{8 Weeks } \\
\hline VEGF & $453.5 \pm 89.1 \mathrm{pg} / \mathrm{ml}$ & $408.4 \pm 98.4 \mathrm{ng} / \mathrm{ml}$ & 0.96 & \\
\hline BDNF & $32.8 \pm 9.2 \mathrm{pg} / \mathrm{ml}$ & $27.3 \pm 8.9 \mathrm{ng} / \mathrm{ml}$ & 0.78 & \\
\hline
\end{tabular}

Systems). Twenty age-matched healthy controls were recruited for VEGF and BDNF estimation.

\section{Neurorehabilitation Regime}

Motor imagery training using Xbox and mirror therapy were administered to the affected upper limb with bilateral hands focusing on principles of learning. Small hand muscle exercises like ball squeezing, lifting an object, rolling a cylindrical shape, and thrust release (mass finger extension) were included in the protocol. General aerobic exercise training was administered with $10 \mathrm{~min}$ of static cycling and brisk walk (the extent the patient can), partial squats (hold for 7 s), and step up and down [20, 21].

\section{Statistics}

Statistical analysis was performed by SPSS version 17 . The comparative data between the two groups were expressed as the mean/median with SD and quartiles. Parametric paired $t$ test was used for intragroup and independent-samples t test for intergroup comparisons with statistically significant $\mathrm{p}=0.05$. Two-way repeated-measures ANOVA was used to compare motor function scores at different time points. The analysis was two-tailed unless otherwise specified. For correlative analysis, the Spearman rank correlation coefficient ( $\mathrm{r}$ ) was calculated. Analysis was done to identify differences in growth factor expression in chronic stroke, in relation to stroke subtypes and etiology, with clinical disability, including short-term follow-up. 

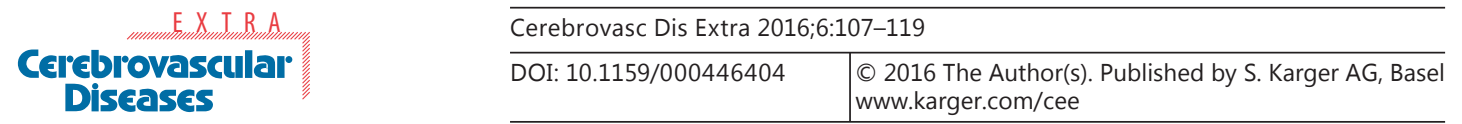

Bhasin et al.: Paracrine Mechanisms of Intravenous Bone Marrow-Derived

Mononuclear Stem Cells in Chronic Ischemic Stroke

Table 2. Mean clinical scores and mononuclear stem cell CD34+ (UD: undisclosed) in groups 1 and 2

\begin{tabular}{|c|c|c|c|c|c|c|c|c|c|}
\hline \multirow{2}{*}{$\begin{array}{l}\text { Case } \\
\text { No. }\end{array}$} & \multirow{2}{*}{$\begin{array}{l}\text { Age/sex/ } \\
\text { weight, kg }\end{array}$} & \multirow{2}{*}{$\begin{array}{l}\text { Area of infarct, all MCA } \\
\text { territory }\end{array}$} & \multirow{2}{*}{$\begin{array}{l}\text { Time after } \\
\text { stroke, } \\
\text { months }\end{array}$} & \multirow[t]{2}{*}{ Cells } & \multirow{2}{*}{$\begin{array}{l}\text { CD34+ } \\
\text { cells, } \%\end{array}$} & \multicolumn{2}{|c|}{ Baseline } & \multicolumn{2}{|c|}{8 weeks } \\
\hline & & & & & & $\begin{array}{l}\text { FM } \\
(/ 66)\end{array}$ & $\begin{array}{l}\mathrm{mBI} \\
(/ 100)\end{array}$ & $\begin{array}{l}\text { FM } \\
(/ 66)\end{array}$ & $\begin{array}{l}\mathrm{mBI} \\
(/ 100)\end{array}$ \\
\hline \multicolumn{10}{|c|}{ Group 1} \\
\hline 1 & $55 / M / 62$ & Rt frontotemporal & 12 & UD & UD & 22 & 47 & 36 & 65 \\
\hline 2 & $52 / \mathrm{M} / 70$ & Lt corona radiata & 9 & UD & UD & 34 & 53 & 51 & 70 \\
\hline 3 & $45 / F / 57$ & Rt frontal Rt striatocapsular & 5 & UD & UD & 32 & 50 & 50 & 74 \\
\hline 4 & $36 / \mathrm{M} / 71$ & Lt temporal parietal & 14 & UD & UD & 25 & 42 & 40 & 53 \\
\hline 5 & $57 / \mathrm{M} / 59$ & Rt PLIC & 12 & UD & UD & 18 & 39 & 26 & 53 \\
\hline 6 & $60 / \mathrm{M} / 58$ & Lt caudate, parietal lobe & 10 & UD & UD & 12 & 45 & 22 & 55 \\
\hline 7 & $53 / \mathrm{M} / 60$ & Lt IC, thalamus & 11 & UD & UD & 20 & 45 & 45 & 60 \\
\hline 8 & $46 / \mathrm{M} / 46$ & Rt frontotemporal & 7 & UD & UD & 17 & 47 & 32 & 72 \\
\hline 9 & $40 / \mathrm{M} / 47$ & Lt parietal & 8 & UD & UD & 34 & 49 & 49 & 85 \\
\hline 10 & $42 / F / 63$ & Lt PLIC & 9 & UD & UD & 25 & 50 & 46 & 72 \\
\hline Mean & $48.6 / 61.3$ & & 9.7 & UD & UD & 23.9 & 46.7 & 39.7 & 65.9 \\
\hline \multicolumn{10}{|c|}{ Group 2} \\
\hline 1 & $33 / \mathrm{M}$ & Rt lacunar & 5 & UD & UD & 18 & 40 & 20 & 55 \\
\hline 2 & $45 / \mathrm{M}$ & Lt frontotemporal & 9 & UD & UD & 20 & 52 & 31 & 62 \\
\hline 3 & $58 / \mathrm{M}$ & Rt temporoparietal & 15 & UD & UD & 11 & 42 & 20 & 50 \\
\hline 4 & $56 / \mathrm{M}$ & Lt caudate, putamen, temporal & 9 & UD & UD & 24 & 55 & 36 & 65 \\
\hline 5 & $42 / \mathrm{M}$ & Rt frontoparietal & 18 & UD & UD & 23 & 50 & 30 & 68 \\
\hline 6 & $60 / \mathrm{M}$ & Rt lentiform, Rt parietal & 8 & UD & UD & 30 & 58 & 49 & 71 \\
\hline 7 & $61 / \mathrm{M}$ & Lt temporal, corona radiata & 18 & UD & UD & 20 & 39 & 45 & 58 \\
\hline 8 & $60 / \mathrm{M}$ & Rt putamen & 6 & UD & UD & 31 & 50 & 51 & 78 \\
\hline 9 & $47 / F$ & Lt frontotemporal & 7 & UD & UD & 22 & 42 & 32 & 56 \\
\hline 10 & $49 / \mathrm{M}$ & Lt temporal & 10 & UD & UD & 15 & 34 & 27 & 47 \\
\hline Mean & $48.1 \pm 8.9$ & & 10.5 & & & 21.4 & 46.2 & 34.1 & 61 \\
\hline
\end{tabular}

PLIC = Posterior limb of internal capsule; IC = internal capsule; $\mathrm{Rt}=$ right; $\mathrm{Lt}=$ left; NA = not available.

\section{Results}

Safety and Feasibility: Monitoring of Infusion-Related Toxicity

Different organ systems were tested through various laboratory tests like percent hemoglobin, total leukocyte count, differential leukocyte count, platelets, prothrombin time, liver and kidney function assessed at the 1st, 3rd and 7th day after infusion. These were within normal limits for all patients. Besides hematological parameters, pulmonary, gastrointestinal, hepatic and renal systems were monitored. Neurological assessment was performed until hospital discharge. The safety outcomes included death, adverse events (fatal or nonfatal myocardial infarction), epileptiform discharges and evidence of any new growth in radiological scans. Cell viability, mononuclear stem cell surface markers, bacteria, syphilis, fungi, viral, mycoplasma, and endotoxin levels were tested in expansion process and transplantation. There were no early or late adverse reactions during and after transplantation observed until 8 weeks. Pulmonary complications like respiratory distress, tachypnea or infections were not observed.

\section{Cell Dosing and Characterization}

As this was an amendment of our last trial, dosage was kept the same, i.e., 1 million $/ \mathrm{kg}$ body weight. CD34+ cells were characterized, with a mean count of $0.31 \%$ with $62.8 \times 10^{6}$ cells infused. 


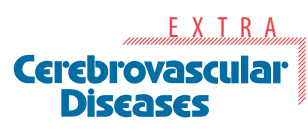

Fig. 1. Mean FM score and $\mathrm{mBI}$ in groups 1 and 2 at 2 months ( $p>$ $0.05)$.

Fig. 2. Box plots showing VEGF in groups 1 and 2 at 8 weeks. No significant difference in the median values of VEGF was found in both groups ( 442.1 vs. $400.3 \mathrm{pg} / \mathrm{ml}$; $\mathrm{p}=$ $0.67)$.

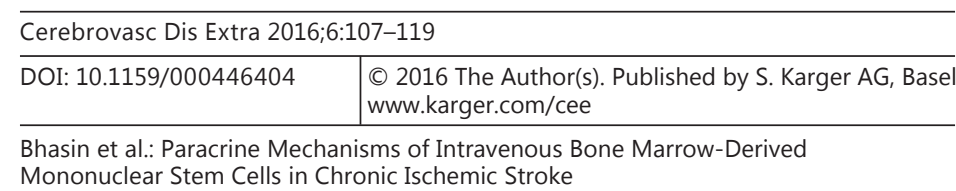

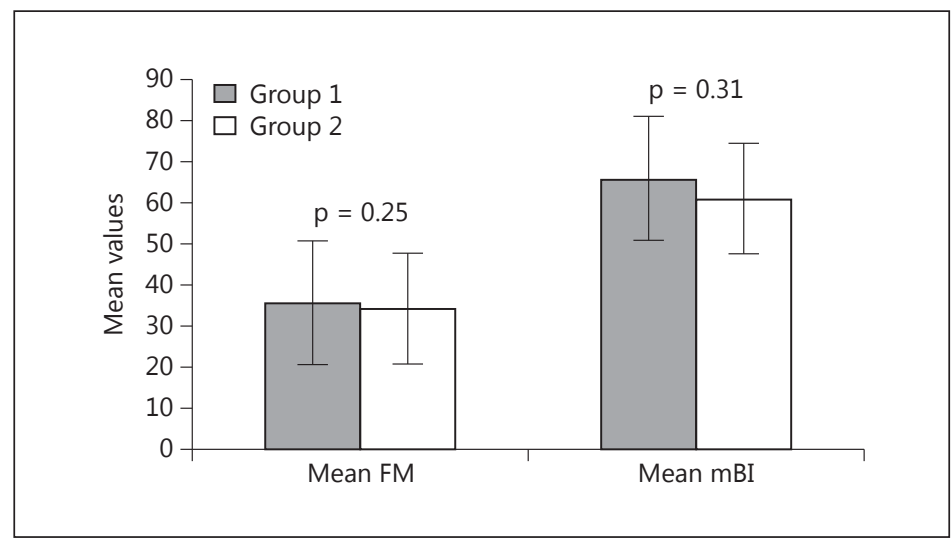

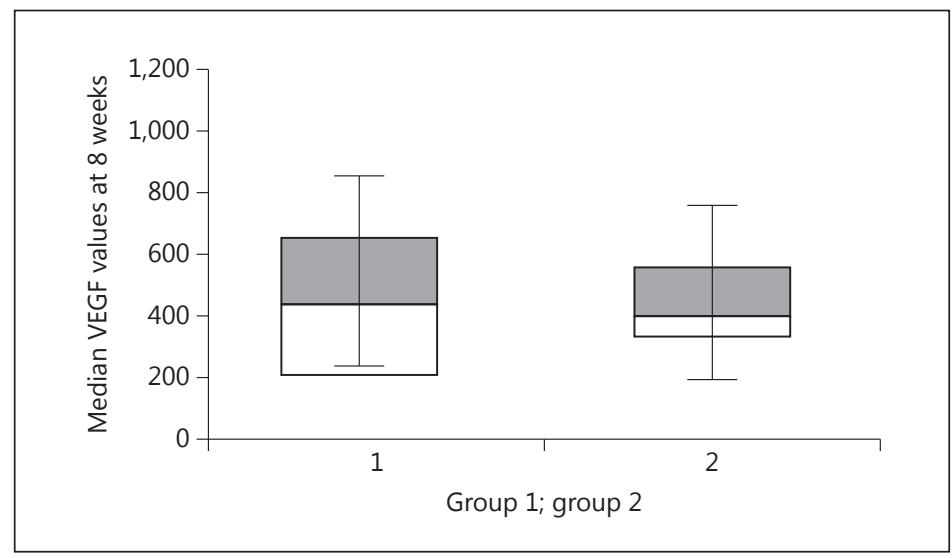

\section{Clinical Scores}

The demographics and baseline characteristics were comparable at baseline. Ischemic stroke classification yielded 8 large-artery (LA), 7 small-artery (SA), 1 cardioembolic (CE) and 4 other (determined and undetermined) strokes. The risk factors were as follows: $55 \%$ hypertensive, $25 \%$ diabetics, $40 \%$ hypercholesterolemia and $4 \%$ alcoholism (table 1 ). In group 1 (male-to-female ratio 8:2, mean age $48.6 \pm 7.1$ years), the mean FM score at baseline was 23.9 \pm 7.5 and at 8 weeks it was $39.7 \pm 10.3(95 \% \mathrm{CI}-24.341$ to $-7.259, \mathrm{p}=0.002)$, whereas the mean $\mathrm{mBI}$ was $46.7 \pm 4.3$ at baseline and $65.9 \pm 10.5$ at 2 months $(95 \% \mathrm{CI}-27$ to $-11.3, \mathrm{p}=$ 0.009 ). In group 2 , the male-to-female ratio was $9: 1$, the mean age was $48.1 \pm 9.1$ years, and the mean FM score was $21.4 \pm 6.1$ and $34.1 \pm 10.3$ at baseline and 8 weeks, respectively ( $95 \%$ CI -9.7 to $-4.3, p=0.04$ ) (table 2). The mean $\mathrm{mBI}$ at baseline was $46.2 \pm 7.8$ and $61 \pm 9.8$ at 2 months of follow-up ( $95 \%$ CI -11.4 to $-7.8, p=0.01)$. The MRC and Ashworth tone scale did not show any significant improvement between baseline and 2 months in all patients.

Comparing the two groups, no statistically significant difference was observed in the activities of daily living scale $\mathrm{mBI}(95 \% \mathrm{CI} 14.3-4.5, \mathrm{p}=0.31)$ and FM score at 2 months $(95 \%$ CI 15.2-5.35, $\mathrm{p}=0.25$ ) (fig. 1). The Ashworth tone scale and the MRC grade for hand muscles remained statistically nonsignificant at 2 months between groups 1 and 2 ( $p>0.05)$.

Serum VEGF and BDNF Expression Levels

Twenty healthy age-matched controls had a mean VEGF level of $257 \pm 102.3 \mathrm{pg} / \mathrm{ml}$ and a BDNF level of $16.6 \pm 3.4 \mathrm{ng} / \mathrm{ml}$. The baseline VEGF and BDNF levels were similar $(\mathrm{p}=0.42$ 


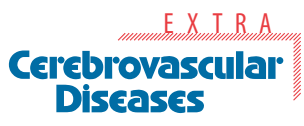

Fig. 3. Graph showing mean VEGF in ischemic stroke. All patients with LA disease were found to have a high mean baseline VEGF in groups 1 and 2 followed by SV. One patient with CE stroke had a VEGF level of $316.4 \mathrm{pg} / \mathrm{ml}$, patients with undetermined (UND) or determined (DET) stroke each had a mean VEGF level of 245.5 or $256.7 \mathrm{pg} / \mathrm{ml}$.

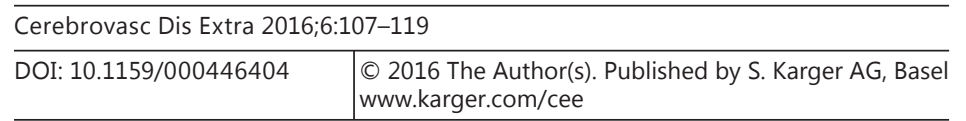

Bhasin et al.: Paracrine Mechanisms of Intravenous Bone Marrow-Derived Mononuclear Stem Cells in Chronic Ischemic Stroke

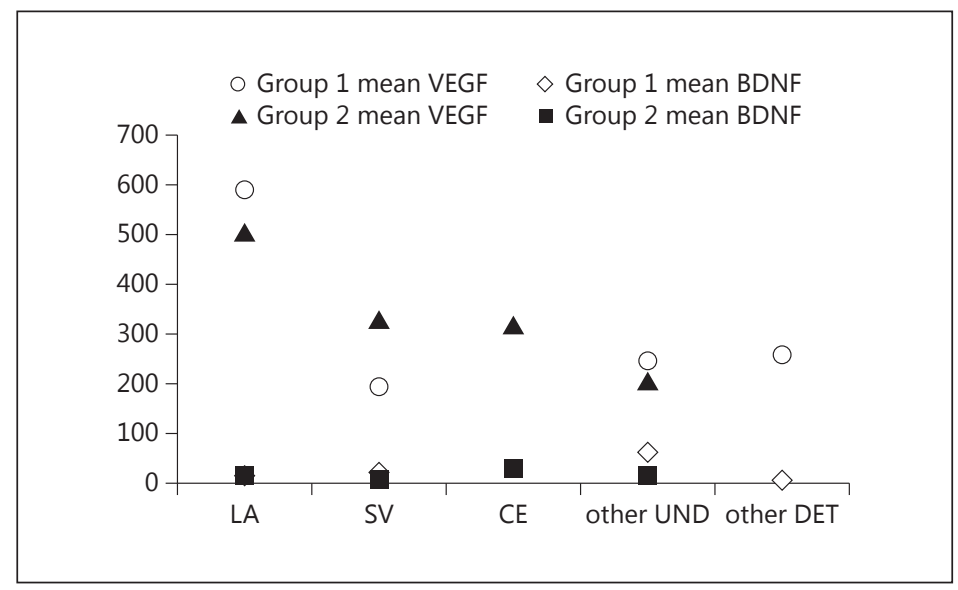

and $\mathrm{p}=0.56$, respectively) and hence were compared at 8 weeks. Mean VEGF at baseline was $336 \pm 78.6 \mathrm{pg} / \mathrm{ml}$ in group 1 and $370 \pm 91.3 \mathrm{pg} / \mathrm{ml}$ in group 2. All patients showed improvement within the groups at 8 weeks ( $\mathrm{p}<0.05)$, but no statistically significant difference was observed between the two groups at 8 weeks (mean $453.5 \pm 89.1$ vs. $408.4 \pm 93.3 \mathrm{pg} / \mathrm{ml}, 95 \%$ CI $13.3-$ $6.7, \mathrm{p}=0.96)$. The median values for VEGF between the groups 1 and 2 were also nonsignificant at 8 weeks (fig. 2) ( 442.1 vs. $400.3 \mathrm{pg} / \mathrm{ml}, \mathrm{p}=0.67$ ).

In group 1, mean BDNF at baseline was $18.7 \pm 6.6$ and $16.1 \pm 7.6 \mathrm{ng} / \mathrm{ml}$ in group 2 . There was no difference observed within the groups at 8 weeks $(p=0.45$ and $p=0.68$ for group 1 and group 2, respectively). No statistically significant improvement was observed between the groups (mean $32.8 \pm 9.2$ vs. $27.3 \pm 9.1 \mathrm{ng} / \mathrm{ml} ; 95 \%$ CI 5.7-1.2, $\mathrm{p}=0.78$ ) after 8 weeks of cell transplantation.

\section{Correlation of Growth Factors with Stroke Subtype and Motor Recovery}

Out of 20 patients, all patients with LA disease were found to have a mean baseline VEGF of $500.9 \mathrm{pg} / \mathrm{ml}$ followed by small-vessel (SV) ( $\mathrm{p}=0.01$, Mann-Whitney U test, one-tailed) and other stroke types, whereas 1 patient with CE stroke had a VEGF level of $316.4 \mathrm{pg} / \mathrm{ml}$. BDNF showed the opposite, i.e, a high BDNF level was observed in stroke patients with other undetermined etiology followed by LA and SA strokes, with $28.2 \mathrm{ng} / \mathrm{ml}$ in 1 CE stroke (fig. 3). There was no causal relationship observed with risk factors, infarct size, or other laboratory parameters (platelets) for both BDNF and VEGF (Spearman coefficient $r=0.34, p=0.56$ ). We divided patients according to severity: severely affected (MRC grade $=1$ with an FM score $\leq 25$ ) and moderately affected (MRC grade $>2 \leq 3$ with an FM score of $\sim 25-45$ ) and correlated them with the serum factors. Eleven of 20 patients were severely affected, with baseline median values of VEGF and BDNF concentrations of 316.4 (interquartile range 471.8-166.1) and 12.5 $\mathrm{ng} / \mathrm{ml}$ (interquartile range 23.7-4.05), respectively. On the other hand, mean concentrations of VEGF in moderately affected patients at 2 months were 314.8 versus $289.8 \mathrm{pg} / \mathrm{ml}$ (95\% CI $\sim 116.4-66.5, \mathrm{p}=0.45)$ and in the severely affected group 592.1 versus $487.6 \mathrm{pg} / \mathrm{ml}(\mathrm{p}=0.76)$ without any statistically significant improvement. BDNF also showed statistically insignificant results, with the severely affected group having a mean BDNF level of $28.1 \mathrm{ng} / \mathrm{ml}$ in group 1 and $23.5 \mathrm{ng} / \mathrm{ml}$ in group 2, and the same was observed in the moderately affected group (38.1 vs. $30.4 \mathrm{ng} / \mathrm{ml}, \mathrm{p}=0.32$ ) (fig. $4 \mathrm{a}, \mathrm{b}$ ). 


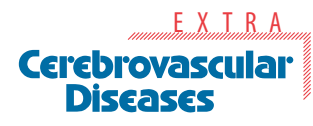

Fig. 4. a Association of serum VEGF according to stroke severity (severely and moderately affected patients) at baseline and at 2 months in groups 1 and 2. b Association of serum BDNF according to stroke severity (severely and moderately affected patients) at baseline and at 2 months in both groups.

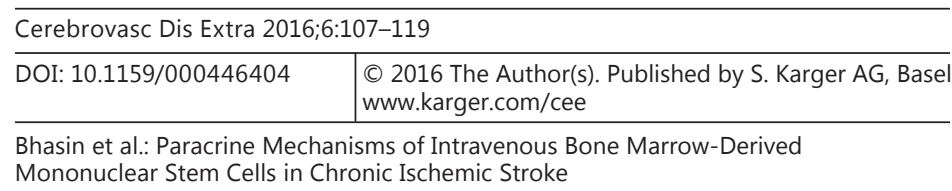

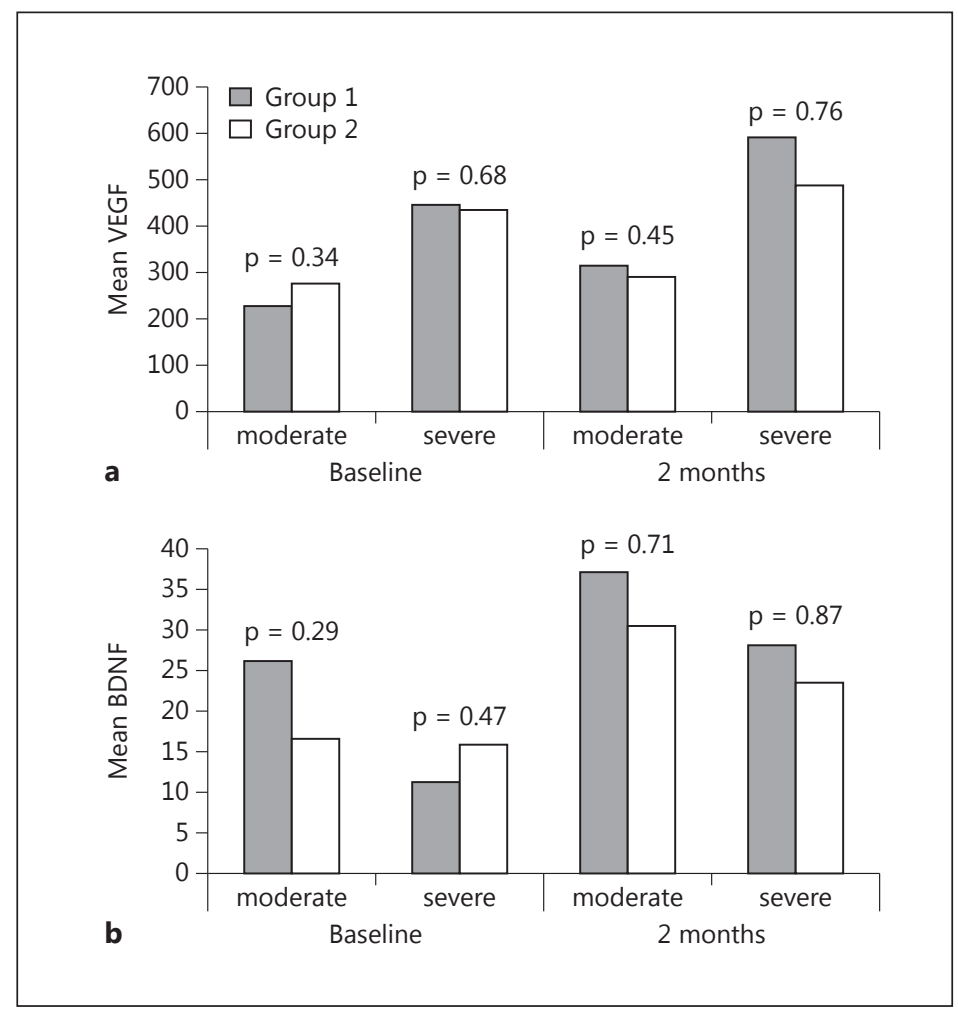

\section{Discussion}

The hypothesis that stem cells work through paracrine signaling is being widely studied. It is defined as a communication between two different cells where one releases chemical mediators to its immediate environment, which leads to a change in behavior of a cell in its adjacent territory $[2,14]$. Autologous intravenous stem cell therapy is safe and feasible in chronic stroke as evidenced by this report and has been established by us in our previous trials as well $[22,23]$ in which we used both naive, i.e., mononuclear, and culture-expanded, i.e., mesenchymal, stem cells. The endogeneous or intrinsic recovery mechanisms start just after an acute insult and are completed by 3 months. The exogenous recovery continues over a longer period, through cell-based therapies, gene therapy, neuromotor rehabilitation and others [3]. We recruited patients between 3 months and 1.5 years after the index event, so that the spontaneous recovery is over. As gliosis and scarring of the brain tissue appears beyond 2 years, we had screened patients within this range.

A mean of $59.9 \times 10^{6}$ mononuclear stem cells (each) were easily procured from 10 bone marrow samples in 1-2 h of culture procedure. Earlier studies received 50 million cells twice [24], 200-400 million cells [25], 34.6 million cells and 5-10 million cells [26]. Compared to our last trial, this study is a randomized placebo-controlled study with the same cell dosage. Savitz et al. [27], in a recent study, conducted autologous mononuclear stem cell transplantation in 10 subjects. Eight received 10 million cells/kg body weight, 1 received 7 million cells/kg body weight, and 1 received 8 million/kg body weight. There was no difference observed in functional outcomes with the three kinds of dosage. STARTING-2 collaborators have suggested autologous culture-expanded mesenchymal stem cells to a dose of $1 \times 10^{6}$ cells $/ \mathrm{kg}$, the equivalent human dose found to be effective in a rat stroke model $\left(1 \times 10^{5}\right.$ to 3 $\times 10^{6}$ cells/rat) based on mean body weight [28]. Cell-enhanced recovery has been reported 

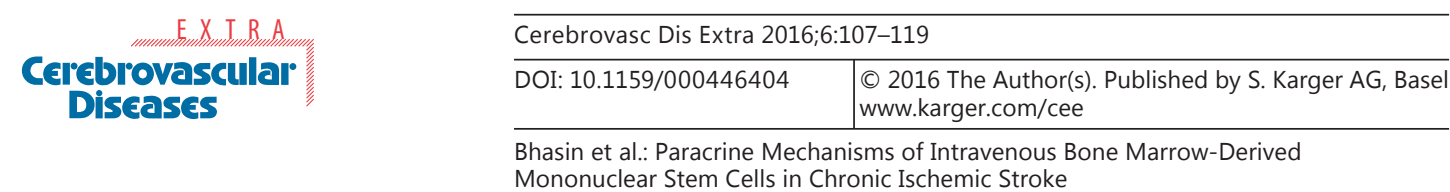

with chronic delivery of cells even at 1 month after ischemia [29]. The best route of transplantation still needs to be established although many clinical trials are opting intravenous as the mode of transplantation being safe and easily tolerable [30].

A very recent study published by Prasad et al. [31] investigated the safety and efficacy of intravenous mononuclear stem cell transplantation in subacute ischemic stroke in which 58 patients received a mean of 280.75 million bone marrow stem cells at a median of 18.5 days after stroke onset. There was no significant difference between the bone marrow stem cell arm and the control arm in the Barthel Index score (63.1 vs. 63.6, p = 0.92), modified Rankin scale shift analysis ( $p=0.53$ ) or score $>3$ ( 47.5 vs. $49.2 \%, p=0.85$ ), and NIHSS score (6.3 vs. $7.0, \mathrm{p}=0.53$ ), which is similar to our study, as we did not observe any statistically significant improvement between both groups on Ashworth tone scale, MRC grade, FM scale and mBI (95\% CI 15.2-5.35, $\mathrm{p}=0.25 ; 95 \%$ CI 14.3-4.5, $\mathrm{p}=0.31$, respectively) with a short follow-up until 2 months.

This ongoing study was planned to examine the efficacy not only on clinical, functional and radiological outcome measures but on the release of growth factors (VEGF and BDNF) after 2 months. The growth factors such as bFGF, VEGF, and angiopoietin-1, and cardiac levels of angiogenic ligands are released as a consequence of neural repair after brain insult [32,33]. BDNF is involved in many facets of brain function, including neuroplastic changes that underlie motor learning. It exerts its effects on neuroplasticity by facilitating long-term potentiation, by promoting dendritic growth and remodeling [34, 35]. This was observed in all the patients who had been administered a neuromotor regime for 2 months. Patients in group 2 showed a statistically significant increase (baseline to 8 weeks) in BDNF as compared to VEGF ( $p=0.01$ vs. $p=0.53$ ) indicating that BDNF is more likely to be involved in neuroplastic changes, which is supported by the literature [36]. Several animal studies have demonstrated significantly increased BDNF mRNA levels in the rat hippocampus after a single bout of $6 \mathrm{~h}$ voluntary wheel running [37]. The percent gain in BDNF was high compared to VEGF (68 vs. $20 \%$ ), suggesting that unlike other growth factors, BDNF is secreted in the central nervous system and blood stream through both repair initiated and an activity-dependent pathway. The activity-dependent secretion is crucial to the role of BDNF in promoting neuroplasticity in circuits activated in response to enrichened experience, i.e., stem cells along with exercise [38]. In a related work [39], it was found that a critical amount or 'threshold' of poststroke rehabilitation must be met to obtain functional recovery. Animals exceeding this threshold exhibited forelimb recovery and showed significant increases in motor cortex BDNF levels, while rats receiving less rehabilitation did not recover and BDNF levels remained at control levels. All groups received motor imagery and aerobic form of training for 8 weeks, which was $1 \mathrm{~h}$ in the hospital settings and rest exercises were advised at home. These findings indicate that BDNF also plays a key role in poststroke rehabilitation and consequently BDNF may be an important target to enhance recovery in stroke patients. Serum BDNF levels rise during aerobic exercise, and quickly return to baseline levels upon exercise cessation, approximately 10-15 min after exercise offset [40].

The mean concentration of both VEGF and BDNF in the serum of patients with stroke was significantly higher than that of the healthy controls. VEGF is a key mediator of angiogenesis, which is an important process leading to reperfusion of ischemic brain tissue after acute stroke [41]. An increase in VEGF was observed from baseline to 2 months but did not reach statistically significant levels in both groups. Mean VEGF expression was lowest in the serum of patients with SV, increasing in stroke with other origin and being the greatest in LA stroke in both groups, suggesting that VEGF could be a marker indicating the size of the infarct, which is supported by previous literature $[42,43]$. We did not find any correlation with platelets in any of our patients. It has been observed that transplantation of bone marrow mesenchymal stem cells into ischemic brain resulted in gain of coordinated function in rats 
due to bone marrow cell soluble factor release, resulting in inhibited scar formation, increased angiogenesis and neuronal commitment [44, 45]. Matsuo et al. [46] posited that increased plasma VEGF values last for at least 90 days in all stroke subtypes, and the clinical significance varies for different stroke types. It was found that the severely affected group had a high mean VEGF of 592.1 versus $487.6 \mathrm{pg} / \mathrm{ml}(\mathrm{p}=0.76)$, without any statistically significant improvement between groups 1 and 2 (fig. 4a, b). Serum VEGF at baseline was higher in severely affected patients than in moderately affected patients ( $316.1 \mathrm{vs.} 257.4 \mathrm{pg} / \mathrm{ml}$ ), which remained high at 2 months predicting a good functional recovery, suggesting that in chronic strokes (without classification into stroke subtype and volume), VEGF might have been increased already at acute onset in severely affected patients and function as an angiogenic [47] and neuroprotective molecule. Thus, higher VEGF values would attenuate neuronal death and reduce infarct volume, although infarct volumes are not depicted in this analysis.

Senescence in stem cells is one phenomenon that is currently being studied and recently published data suggest that their efficacy is limited by natural aging [48]. The impact of aging on stem cell populations differs between tissues and depends on a number of intrinsic/ extrinsic factors, including systemic changes associated with immune system alterations. The mean age of patients in our study was a relatively younger population ( $48.6 \pm 9.6$ years), so we assume that efficacy was not greatly compromised. Comorbid or risk factors like age, hypertension, or diabetes were observed in our group, but we did not find any correlation with the cell effects nor did we find a low yield in the correlation with these risk factors. The bone marrow harvest from each patient was not compromised in spite of all the risk factors. Owing to ethical concerns and rampant use of stem cells without regulation, the institute ethics committee gave approval for 10 patients initially. These patients will be followed up for up to 6 months to 2 years to gauge the efficacy in terms of serum growth factor, spectroscopic analysis and functional imaging. Both groups showed improvement with increased clinical and activity of daily living scores, which would urge the researchers to ponder over psychoimmunological/placebo effects of mononuclear stem cells.

Doll et al. [49], in a review article, reported that an increase in the production of proinflammatory cytokines and a decrease in the production of anti-inflammatory cytokines are correlated with a larger infarct size and worse clinical outcome. TNF- $\alpha$, IL-1 $\beta$, IL- 6 and IL-10 are some cytokines that are known to get upregulated after acute stroke. IL- 6 is elevated in plasma during the first week after stroke, while IL-1 $\beta$ is elevated in the cerebrospinal fluid of severe stroke patients with peak levels at $2-3$ days. TNF- $\alpha$-positive neurons peak between 2 and 3 days after stroke and TNF- $\alpha$-positive astrocytes peak between $15 \mathrm{~h}$ and 14 days. Proinflammatory cytokines after mononuclear stem cell infusion has also been reported [50]. Since this trial studies mononuclear stem cell infusion in the chronic stage of stroke, where acute inflammatory pathways might have stabilized, cytokine measurement might not serve as a good marker. Cytokines released from mononuclear stem cells can be measured and may account as another outcome measure to study efficacy in future trials.

There is evidence suggesting that human neural stem cells, human umbilical cord blood and BM-MNCs secrete glial cell-derived neurotrophic factor and BDNF, IGF-1 and VEGF, which may protect dysfunctional motor neurons, thereby prolonging the lifespan of the strokeinduced animals [51]. They are known to secrete NT-3, which supports the survival, and differentiation of existing stroke-induced damage to the brain and central nervous system caused by focal or global ischemia [52, 53].

The pathophysiology of stroke within the first few days includes infarct progression, active inflammation and edema formation and loss of autoregulatory control from the brain. The acute and subacute phase may not be conducive for cell transplantation. Stem cell research is in the nascent stage and is being studied in all stages of stroke. In chronic stroke, the rationale of cell infusion is upregulation of growth factors, prevention of ongoing cell 
death, enhancement of synaptic connectivity between the host and graft, cell differentiation and integration acting as scaffolds and chaperons. A very small sample size, dose of cells, site/ mode of transplantation, no fMRI data analyzed and lack of in vivo monitoring of the intravenously transplanted cells are a few limitations which do not infer efficacy of BM-MNC in chronic stroke patients. The heterogeneity of stroke, infarct etiologies, topography, injury location and size are hurdles to prove the same. The interim analysis shows that the research may be continued as no risk was observed in both groups, which indicates that cell transplantation was safe in 10 of these patients.

\section{Conclusion}

Novel research directions aspire to use hematopoietic stem cells as biologically active drug delivery vehicles to facilitate tissue regeneration. Autologous intravenous mononuclear stem cell transplantation is safe and feasible. No conclusion on efficacy can be addressed with this report. It is likely that the paracrine mediators are expressed/released in a temporal and spatial manner after stem cell infusion and exercise training exerting different effects depending on the microenvironment of the host after injury.

\section{Acknowledgement}

The study is funded by the Department of Science and Technology, under the Ministry of Science, New Delhi, India. All authors have contributed equally.

\section{Disclosure Statement}

The authors have no conflicts of interest to disclose.

\section{References}

1 Bjorklund A, Lindvall 0: Cell replacement therapies for central nervous system disorders. Nat Neurosci 2000; 3:537-544.

-2 Goldman SA, Windrem MS: Cell replacement therapy in neurological disease. Philos Trans R Soc Lond B Biol Sci 2006;361:1463-1475.

3 Scadden DT: Stem cell niche as an entity of action. Nature 2006;441:1075-1079.

4 Cramer SC: Repairing the human brain after stroke: I. Mechanisms of spontaneous recovery. Ann Neurol 2008; 63:272-287.

5 Domen J, Weissman IL: Self-renewal, differentiation or death: regulation and manipulation of hematopoietic stem cell fate. Mol Med Today 1999;5:201-208.

-6 Brennemann M, Sharma S, Harting M, Strong R, Cox CS: Autologous bone marrow mononuclear cells enhance recovery after acute ischemic stroke in young and middle-aged rats. J Cereb Blood Flow Metab 2010;30:140149.

7 Anthony DF, Sheils PG: Exploiting paracrine mechanisms of tissue regeneration to repair damaged organs. Transplant Res 2010;2:13-17.

8 Barnaik PR, Devitt TC: Stem cell paracrine actions and tissue regeneration. Regen Med 2010;5:121-143.

-9 Tsukahara T, Yonekawa Y, Tanaka K, Ohara O, Wantanabe S, Kimura T, et al: The role of brain-derived neurotrophic factor in transient forebrain ischemia in the rat brain. Neurosurgery 1994;34:323-331.

-10 Schabitz WR, Steigleder T, Cooper-Kuhn CM, Schwab S, Sommer C, Schneider A, et al: Intravenous brainderived neurotrophic factor enhances post stroke sensorimotor recovery and stimulates neurogenesis. Stroke 2007;38:2165-2172.

11 Zachary I: Neuroprotective role of vascular endothelial growth factor: signalling mechanisms, biological function, and therapeutic potential. NeuroSignals 2005;14:207-221. 
Bhasin et al.: Paracrine Mechanisms of Intravenous Bone Marrow-Derived

Mononuclear Stem Cells in Chronic Ischemic Stroke

-12 Jin K, Zhu Y, Sun Y, Mao XO, Xie L, Greenberg DA: Vascular endothelial growth factor (VEGF) stimulates neurogenesis in vitro and in vivo. Proc Natl Acad Sci USA 2002;99:11946-11950.

13 Barkho BZ, Zhao X: Adult neural stem cells: response to stroke injury and potential for therapeutic applications. Curr Stem Cell Res Ther 2011;6:327-338.

14 Gnecchi M, Zhang Z, Ni A, Dzau VJ: Paracrine mechanisms in adult stem cell signaling and therapy. Circ Res 2008;103:1204-1219.

15 Loewen SC, Anderson BA: Reliability of motor assessment and Barthel Index. Phys Ther 1999;8:1077-1081.

16 Ismail S, Bilger Y, Evren Y, Rdvani A: Brunnstrom recovery stage and motricity index for the evaluation of upper extremity in stroke: analysis for correlation and responsiveness. Int J Rehabil Res 2009;32:228-231.

17 Oldfield RC: The assessment and analysis of handedness: the Edinburgh inventory. Neuropsychologia 1972; 9:97-113.

18 Bhasin A, Srivastava MVP, Kumaran SS, Mohanty S, Bhatia R: Autologous intravenous mononuclear stem cell transplantation in chronic ischemic stroke. J Stem Cells Regen Med 2012;8:181-189.

19 Bergado JA, Monteagudo CS, Ramirez PH, Gonzalez RM: Autologous bone marrow stem cell transplantation in stroke patients. An open study. Restor Neurol Neurosci 2009;27:151-161.

20 Bhasin A, Srivastava MVP, Kumaran SS, Bhatia R, Mohanty S: Neural interface of mirror therapy in chronic stroke: a functional imaging study. Neurol India 2012;60:570-576.

21 Ploughman M, Austin MW, Glynn L, Corbett D: The effects of poststroke aerobic exercise on neuroplasticity: a systematic review of animal and clinical studies. Transl Stroke Res 2015;6:13-28.

22 Bhasin A, Srivastava MVP, Kumaran SS, Mohanty S, Bhatia R, Garg A, Airan B: Autologous mesenchymal stem cells in chronic stroke. Cerebrovasc Dis Extra 2011;1:93-104.

23 Bhasin A, Srivastava MVP, Kumaran SS, Mohanty S, Bhatia R: Stem cell therapy: a clinical trial in stroke. Clin Neurol Neurosurg 2013;115:1003-1008.

-24 Kondziolka D, Wechsler L, Meltzer C, Goldstein S: Transplantation of cultured neuronal cells for patients with stroke. Neurology 2000;55:565-570.

-25 Savitz SI, Dinsmore J, Wu S: Neural transplantation of fetal porcine cells in patients with basal ganglia infarcts; a preliminary safety and feasibility study. Cerebrovas Dis 2005;2:101-112.

26 Bang OY, Lee JS, Lee PH, Lee G: Autologous mesenchymal stem cell transplantation in stroke patients. Ann Neurol 2005;57:874-882.

27 Savitz SI, Mishra V, Kasam M, Juneja H, Cox CS, Alderman S, Aisiku I, Kar S, Gee A, Grotta JC: Intravenous autologous bone marrow mononuclear cells for ischemic stroke. Ann Neurol 2011;70:59-69.

-28 Kim SJ, Moon GJ, Chang WH, Kim YH, Bang OY; STARTING-2 collaborator: Intravenous transplantation of mesenchymal stem cells preconditioned with early phase stroke serum: current evidence and study protocol for a randomized trial. Trials 2013;14:317.

29 Shen SH, Li Y, Chen J, et al: Therapeutic benefit of bone marrow stromal cells administered 1 month after stroke. J Cereb Blood Flow Metab 2007;27:6-13.

-30 Savitz SI, Misra V, Kasam M, Juneja H, Cox CS, Alderman S, Aisiku I, Kar S, Gee A, Grotta JC: Intravenous autologous bone marrow mononuclear cells for ischemic stroke. Ann Neurol 2011;70:59-69.

31 Prasad K, Sharma A, Garg A, Mohanty S, Bhatnagar S, Johri S, Singh KK, Nair V, Sarkar RS, Gorthi SP, Hassan KM, Prabhakar S, Marwaha N, Khandelwal N, Misra UK, Kalita J, Nityanand S; InveST Study Group: Intravenous autologous bone marrow mononuclear stem cell therapy for ischemic stroke: a multicentric, randomized trial. Stroke 2014;45:3618-3624.

-32 Sobrino T, Arias S, Rodriguez-González R, Brea D, Silva Y, de la Ossa NP, Agulla J, Blanco M, Pumar JM, Serena J, Dávalos A, Castillo J: High serum levels of growth factors are associated with good outcome in intracerebral hemorrhage. J Cereb Blood Flow Metab 2009;29:1968-1974.

-33 Kamihata H, Matsubara H, Nishiue T, Fujiyama S, Tsutsumi Y, Ozono R, Masaki H, Mori Y, Iba O, Tateishi E, Kosaki A, Shintani S, Murohara T, Imaizumi T, Iwasaka T: Implantation of bone marrow mononuclear cells into ischemic myocardium enhances collateral perfusion and regional function via side supply of angioblasts, angiogenic ligands, and cytokines. Circulation 2001;104:1046-1052.

34 Ferris LT, Williams JS, Shen CL: The effect of acute exercise on serum brain-derived neurotrophic factor levels and cognitive function. Med Sci Sports Exerc 2007;39:728-734.

-35 Kleim JA, Jones TA, Schallert T: Motor enrichment and the induction of plasticity before or after brain injury. Neurochem Res 2003;28:1757-1769.

-36 Sun J, Ke Z, Ping Yip P, Hu XL, Zheng XX, KY Tong KY: Gradually increased training intensity benefits rehabilitation outcome after stroke by BDNF upregulation and stress suppression. Biomed Int 2014;92:57-62.

-37 Chen MJ, Russo-Neustadt AA: Running exercise-induced up-regulation of hippocampal brain-derived neurotrophic factor is CREB-dependent. Hippocampus 2009;19:962-972.

-38 Ke Z, Yip SP, Li L, Zheng XX, Tong KY: The effects of voluntary, involuntary, and forced exercises on brainderived neurotrophic factor and motor function recovery: a rat brain ischemia model. PLoS One 2011; 8;6:e16643.

39 Mang CS, Campbell KL, Ross CJ, Boyd LA: Promoting neural plasticity for motor rehabilitation after stroke: considering the effects of aerobic exercise and genetic variation on brain-derived neurotrophic factor. Phys Ther 2013;93:1707-1716. 
40 Rojas Vega S, Strüder HK, Vera Wahrmann B, Schmidt A, Bloch W, Hollmann W: Acute BDNF and cortisol response to low intensity exercise and following ramp incremental exercise to exhaustion in humans. Brain Res 2006;1121:59-65.

-41 Slevin M, Krupinski J, Slowik A, Kumar P, Szczudlik A, Gaffney J: Serial measurement of vascular endothelial growth factor and transforming growth factor beta1 in serum of patients with acute ischemic stroke. Stroke 2000;31:1863-1870.

-42 Cobbs CS, Chen J, Greenberg DA, Graham SH: Vascular endothelial growth factor expression in transient focal cerebral ischemia in the rat. Neurosci Lett 1998;249:79-82.

43 Neufeld G, Cohen T, Gengrinovitch S, Poltorak Z: Vascular endothelial growth factor (VEGF) and its receptors. FASEB J 1999;13:9-22.

44 Lee SC, Lee KY, Kim YJ, Kim SH, Koh SH, Lee YJ: Serum VEGF levels in acute ischaemic strokes are correlated with long-term prognosis. Eur J Neurol 2010;17:45-51.

45 Lennmyr F, Ata KA, Funa K, Olsson Y, Terent A: Expression of vascular endothelial growth factor (VEGF) and its receptors (Flt-1 and Flk-1) following permanent and transient occlusion of the middle cerebral artery in the rat. J Neuropathol Exp Neurol 1998;57:874-882.

46 Matsuo R, Ago T, Kamouchi M, Kuroda J, Kuwashiro T, Hata J, Sugimori H, Fukuda K, et al: Clinical significance of plasma VEGF value in ischemic stroke - research for biomarkers in ischemic stroke (REBIOS) study. BMC Neurol 2013;13:32-39.

-47 Storkebaum E, Lambrechts D, Carmeliet P: VEGF: once regarded as a specific angiogenic factor, now implicated in neuroprotection. Bioessays 2004;26:943-954.

48 Nurkovic JS, Volarevic V, Lako M, Armstrong L, Arsenijevic N, Stojkovic M: Aging of stem and progenitor cells: mechanisms, impact on the therapeutic potential and rejuvenation. Rejuvenation Res 2016;19:3-12.

49 Doll DN, Barr TL, Simpkins JW: Cytokines: their role in stroke and potential use as biomarkers and therapeutic targets. Aging Dis 2014;5:294-306.

50 Sharma S, Yang B, Strong R, Xiao Xi XP, Brenneman M, Grotta JC, Aronowski J, Savitz SI: Bone marrow mononuclear cells protect neurons and modulate microglia in cell culture models of ischemic stroke. J Neurosci Res 2014;88:2869-2876.

51 Hao L, Zou Z, Tian H, Zhang Y, Zhou H, Liu L: Stem cell-based therapies for ischemic stroke. Biomed Res Int 2014;2014:468748..

52 Kalluri HS, Dempsey RJ: Growth factors, stem cells, and stroke. Neurosurg Focus 2008;24:3-8.

53 Lindvall 0, Kokaia Z: Stem cell research in stroke: how far from the clinic?. Stroke 2011;42:2369-2375. 